\title{
Fabricação de lã de rocha a partir da escória da produção de ligas FeSiMn
}

\section{(Manufacture of mineral wool from slag of ferroalloy production FeSiMn)}

\author{
G. F. Rodrigues ${ }^{1}$, J. O. Alves ${ }^{1,2}$, J.A.S. Tenório ${ }^{1}$, D. C.R. Espinosa ${ }^{I}$ \\ ${ }^{1}$ Departamento de Engenharia Metalúrgica e de Materiais, Escola Politécnica da Universidade de S. Paulo, Av. \\ Prof. Mello Morais 2463, Cidade Universitária S. Paulo, SP 05508-030 \\ ${ }^{2}$ Centro de Pesquisa - Arcelor Mittal Inox Brasil, Pça. $1^{\circ}$ de Maio 09, Centro, Timóteo, MG \\ girleyf@gmail.com
}

\begin{abstract}
Resumo
Este trabalho visou o estudo da produção de lã de rocha utilizando escória da produção de ligas de ferro silício manganês. O resíduo em questão possui características químicas que indicam a possibilidade de adição deste resíduo em formulações de lãs minerais. Procedeu-se a fusão da escória em um forno elétrico a arco, em escala de laboratório. A escória foi fundida e vazada na temperatura de $1450{ }^{\circ} \mathrm{C}$ em um recipiente com água, visando um resfriamento brusco e com isso uma aproximação do método de produção das lãs de rocha. Amostras da lã de rocha produzida foram caracterizadas por técnicas de análise química, difração de raios X, microscopia eletrônica de varredura e análise térmica diferencial sendo que, os resultados obtidos foram comparados aos valores encontrados na literatura. Os resultados encontrados mostram que a reciclagem dos resíduos para a produção de lãs de rocha é promissora, pois o reaproveitamento da escória de ferro silício manganês permite a transformação destes resíduos em subprodutos através da incorporação dos resíduos na produção de lã de rocha, que possui amplo mercado como isolante térmico, acústico e inibidor de propagação de chamas.

Palavras-chave: escória, reciclagem, lã de rocha.
\end{abstract}

\begin{abstract}
This study aimed to investigate the production of rock wool using slag from the production of ferrosilicon manganese alloys. The waste in question has chemical characteristics that indicate the possibility of adding this in formulations of mineral wool. There has been melting the slag in an electric arc furnace in laboratory scale. The slag was melted and poured at a temperature of $1450{ }^{\circ} \mathrm{C}$ in a container with water, aiming at a rapid cooling and thus an approximation of the method of production of rock wool. Samples of rock wool produced were characterized by techniques of chemical analysis, X-ray diffraction, scanning electron microscopy and differential thermal analysis is that the results were compared to those found in the literature. The results show that the recycling of waste for the production of rock wool is promising, for the reuse of slag from ferrosilicon manganese allows the conversion of waste products through the incorporation of waste in the production of rock wool, which has broad market as insulation thermal, acoustic and inhibiting the spread of flames.
\end{abstract}

Keywords: slag, recycling, rock wool.

\section{INTRODUÇÃO}

As lãs de rocha são constituídas por fibras, que podem ser ou não impregnadas com um agente aglutinante. Devido a suas propriedades de isolamento térmico, isolamento acústico, proteção contra incêndios, quimicamente neutra e resistência a água, atende aos mercados de construção civil, industrial, automotivo, eletro-eletrônico, entre outros [1]. As lãs de rocha podem ser moldadas em diversas maneiras para as mais diversas aplicações e devido à sua elasticidade, as lãs de rocha podem ser compactadas para reduzir o seu volume durante o acondicionamento, tornando-o mais barato e mais fácil de transportar e de manusear. Lãs de rocha fazem parte do grupo das lãs minerais, que são materiais inorgânicos de isolamento feito de fibras. Em outubro de 2001, a International Agency for Research on Cancer (IARC), órgão subordinado a ONU, reclassificou todo esse grupo das lãs minerais para o chamado grupo III de produtos, ou seja, os não classificáveis como cancerígenos para os seres humanos. Antes disto, a IARC classificava estas lãs como pertencentes ao grupo $2 \mathrm{~B}$, de produtos possivelmente cancerígenos, no qual ainda se encontram as lãs cerâmicas e de amianto. Para chegar a esta conclusão, a IARC levou em conta a biossolubilidade das partículas inaláveis das lãs [2].

A escória de FeSiMn é um resíduo gerado na produção da liga de ferro silício manganês (FeSiMn). Esta liga faz parte do grupo das chamadas ligas de manganês. As ligas de manganês compreendem quatro tipos de ligas. Uma é a liga de FeSiMn, que possui a maior produção [3] dentre as quatro ligas de manganês, as outras são três classificadas em categorias de acordo com o seu teor de carbono: Ferro Manganês Alto Carbono, representado por FeMnAC 
(6-7\% de carbono), Ferro Manganês Médio Carbono representado por FeMnMC (1-2\% de carbono) e Ferro Manganês Baixo Carbono representado por FeMnBC (0,1-0,5\% de carbono). A liga de ferro silício manganês (FeSiMn) apresenta teores que variam de 12 a $25 \%$ de silício. A produção nacional do setor de ferroligas à base de manganês alcançou 687 mil t sendo que deste total cerca de 350 mil t da liga de FeSiMn no ano de 2007 [3].

A escória é gerada no processo de fabricação das ligas a partir do material de ganga associada a minérios bem como os fluxantes adicionados à carga. Os fluxantes são adicionados para atuarem: auxiliando na fundição, na atividade dos óxidos na escória, na temperatura de fusão da escória, na viscosidade e condutividade elétrica. A geração de escória para a produção da liga $\mathrm{FeSiMn}$ por uma única empresa situada no Brasil no ano de 2003 foi de 112 mil t [4]. Entre as aplicações para a escória, são citadas: base para a pavimentação de estradas, lastro para ferrovia [4], produção de aços com baixo teor de manganês $[5,6]$, e na maioria das empresas produtoras a escória é descartada. Estudos sobre a avaliação ambiental da escória de ferro-manganês que foi utilizada como revestimentos de pavimentos na cidade de Salvador no estado da Bahia - Brasil, concluíram que os resíduos não podem ser classificados como inerte conforme a NBR 10004 [4].

O processo de vitrificação é citado como uma forma de imobilização de resíduos [7]. As lãs de rocha possuem uma composição química formada por vários óxidos e com isso possuem a capacidade de absorver em sua composição resíduos formados por óxidos [8]. O comportamento térmico e a morfologia são características importantes deste tipo de material [9-12]. A incorporação de resíduos na fabricação de produtos é uma alternativa de aproveitamento de resíduos de forma a não agredir o meio ambiente [13]. A utilização de resíduos siderúrgicos na produção de produtos de forma segura é investigada [14-16]. Neste contexto de reciclagem de resíduos, este trabalho foi realizado com o intuito de estudar a produção de lã de rocha utilizando a escória da produção de ligas de FeSiMn, através da caracterização das fibras produzidas. As lãs de rocha quando comparadas com as fibras de amianto possuem a vantagem de não serem tão danosas a saúde humana $[8,12]$. Com isso as fibras de lã de rocha podem substituir as fibras de amianto em algumas aplicações. As lãs de rocha são materiais que possuem um amplo mercado consumidor, pois tradicionalmente são usadas como isolantes térmicos e acústicos, e possuem aplicação na construção civil e setores industriais que utilizam sistemas de isolação térmica ou acústica.

\section{MATERIAIS E MÉTODOS}

A matéria prima utilizada neste trabalho foi escória da produção da liga de ferro silício manganês. A escória é constituída por uma parte mais fina formada por um pó e também por pedaços de rocha, que apresentam distribuição de tamanho variando de $2 \mathrm{~cm}$ a $14 \mathrm{~cm}$, não sendo possível colocar no forno, sendo necessária a sua cominuição. A cominuição foi feita em um britador de mandíbulas Furlan BM 2010; em seguida o material foi peneirado em peneira ABN 5/16" com abertura 7,93 mm, sendo utilizado o material passante. A escória foi fundida em um forno elétrico a arco em escala de laboratório Detroit monofásico 10 N 912-K de $15 \mathrm{~kW}$ de potência máxima; o material fundido foi vazado a $1450{ }^{\circ} \mathrm{C}$ em água para a obtenção de um material vítreo, secado em uma estufa a $90{ }^{\circ} \mathrm{C}$ por $24 \mathrm{~h}$ e caracterizado por análise química de fluorescência de raios $\mathrm{X}$, análise térmica diferencial, difração de raios $\mathrm{X}$ e microscopia eletrônica de varredura. A análise química foi em um espectrômetro de fluorescência de raios X por dispersão de comprimento de onda Philips PW2404 e a análise térmica diferencial em um equipamento Netzsch 409 C. Ambos os cadinhos porta amostra e de referência foram de alumina, sendo o ensaio ao ar com taxa de aquecimento $15^{\circ} \mathrm{C} / \mathrm{min}$ da temperatura ambiente até $1480{ }^{\circ} \mathrm{C}$. A caracterização por difração de raios $\mathrm{X}$ foi feita em um difratômetro Philips MPD $1880 \mathrm{com}$ radiação Cuk $\alpha(\lambda=1,5418 \AA)$, potência $40 \mathrm{kV}$ e $40 \mathrm{~mA}$. As condições de análise foram: passo $2^{\circ}$, tempo de passo $1 \mathrm{~s} \mathrm{e}$ intervalo de medida, em $2 \theta$, de $10^{\circ}$ a $70^{\circ}$. A morfologia do material foi caracterizada em um microscópio eletrônico de varredura Philips XL-30, equipado com uma microssonda EDAX para análise espectrométrica de raios $\mathrm{X}$.

\section{RESULTADOS E DISCUSSÃO}

\section{Análise química}

A Tabela I mostra os óxidos em \% de massa que fazem parte da composição química das fibras da lã de rocha produzida e da lã de rocha convencional.

A composição química das lãs de rocha é apresentada como uma faixa de composição, conforme a literatura $[8$, 17] isto ocorre porque comercialmente existem várias lãs de rocha convencionais, que podem ter sua composição química conforme a matéria prima que a deu origem e o processo empregado na fabricação. As lãs de rocha possuem o dióxido de silício como componente principal, e este é o principal óxido formador de vidros. $\mathrm{O} \mathrm{SiO}_{2}$ forma uma rede

Tabela I - Composição química das fibras produzidas da lã produzida e da lã de rocha convencional [8].

[Table I - Chemical composition of the fibers produced wool and rock wool conventional [8].]

\begin{tabular}{cccccccccc}
\hline Óxidos & $\mathrm{SiO}_{2}$ & $\mathrm{CaO}$ & $\mathrm{MgO}$ & $\mathrm{Al}_{2} \mathrm{O}_{3}$ & $\mathrm{MnO}$ & $\mathrm{Fe}_{2} \mathrm{O}_{3}$ & $\mathrm{Na}_{2} \mathrm{O}$ & $\mathrm{K}_{2} \mathrm{O}$ & $\mathrm{TiO}_{2}$ \\
\hline lã produzida (\% em massa) & 67 & 4,1 & 5,2 & 1 & 15 & 1,9 & 1,6 & 3,6 & 0,001 \\
Lã de rocha [8] (\% em massa) & $41-53$ & $10-25$ & $6-16$ & $6-14$ & $0,1-0,3$ & $3-8$ & $1,1-3,5$ & $0,5-2,0$ & $0,9-3,5$ \\
\hline
\end{tabular}


tridimensional. As unidades básicas são tetraedros, onde um átomo de silício está ligado a quatro átomos de oxigênio, de jeito a formar um tetraedro. Os tetraedros são ligados pelos vértices formando uma rede. Outro constituinte que faz parte da composição química das lãs de rocha é o $\mathrm{CaO}$, este óxido juntamente com: $\mathrm{MgO}, \mathrm{Na}_{2} \mathrm{O}$ e $\mathrm{K}_{2} \mathrm{O}$ faz parte do grupo dos óxidos modificadores de rede. Os óxidos modificadores de rede atuam favorecendo a fluidez do vidro fundido. Os óxidos de $\mathrm{Al}_{2} \mathrm{O}_{3}, \mathrm{MnO}$ e $\mathrm{TiO}_{2}$ também fazem parte da composição das lãs de rocha. Estes óxidos fazem parte do grupo de óxidos conhecidos como óxidos intermediários, que desempenham a função de aumentar a durabilidade e a resistência química dos vidros [8].

As fibras produzidas apresentam como constituinte principal o $\mathrm{SiO}_{2}$ e o $\mathrm{MnO}$, estes agem como formador de rede e estabilizador da fase vítrea respectivamente [15]. Os mesmos óxidos são encontrados nas fibras de lã de rocha convencional foram encontrados nas fibras produzidas com a escória de FeSiMn. As formulações para a produção de lã de rocha podem ser diversas [8], pois os óxidos são agrupados em grupos de acordo com suas funções nas formulações de vidros, ou seja pode-se variar a quantidade dos óxidos que constituem a lã de rocha desde que as propriedades da lã permaneçam as mesmas.

\section{Morfologia das fibras}

As fibras das lãs minerais utilizadas como isolante tem diâmetro variando entre $2 \mu \mathrm{m}$ a $9 \mu \mathrm{m}[8,18,19]$. O aspecto uniforme da composição química da fibra obtida é mostrado na Fig. 1.

A imagem da Fig. 1a mostra uma fibra de lã de rocha com diâmetro menor que $10 \mu \mathrm{m}$. Comparando as fibras de lã de rocha com as fibras de amianto, a primeira apresenta a vantagem de não ocorrer fraturas longitudinais, ou seja, não desintregando-se em fibras de diâmetros menores. As fibras de amianto se desintegram em fibrilas com diâmetro médio de $0,02 \mu \mathrm{m}$, e estas fibrilas causam danos a saúde humana [8]. A Fig. 1a mostra a uniformidade química da fibra sem a formação de fases secundárias. Já a análise elementar confirma a presença dos elementos: $\mathrm{O}, \mathrm{Na}, \mathrm{Mg}, \mathrm{Al}, \mathrm{Si}, \mathrm{K}$, $\mathrm{Ca}, \mathrm{Ti}, \mathrm{Mn}$ e $\mathrm{Fe}$. O silício, manganês e o oxigênio são os elementos que aparecem em maior quantidade.

\section{Difração de raios $X$}

$\mathrm{O}$ padrão de difração de raios $\mathrm{X}$ da amostra que foi vazada em água a $1450{ }^{\circ} \mathrm{C}$ é mostrado na Fig. 2 .

É possível observar a ausência de picos de fases cristalinas, o que evidência a característica predominantemente amorfa da fibra, indicando que o processo de resfriamento em água foi suficientemente rápido a fim de garantir a ausência de ordenação, que é uma característica estrutural dos materiais amorfos. Essa característica de material vítreo é importante para as lãs de rocha [8], portanto a lã de rocha produzida compartilha essas mesmas características com as lãs de rocha convencionais.

\section{Análise térmica diferencial}

A análise térmica diferencial (ATD) foi realizada com o intuito de verificar o comportamento térmico da fibra e determinar a temperatura de fusão. A Fig. 3 apresenta a curva de ATD da fibra. O pico exotérmico inicia em torno de $874{ }^{\circ} \mathrm{C}$, referindo-se à cristalização da fibra. $\mathrm{O}$ evento endotérmico que ocorre em torno de $1095{ }^{\circ} \mathrm{C}$ caracteriza a fusão. Esses valores de temperaturas de cristalização e de fusão estão dentro da faixa das lãs de rocha encontrada em normas [8], mostrando que a lã de rocha produzida possui um comportamento térmico semelhante às lãs de rocha convencionais.

As fibras produzidas apresentaram-se translúcidas, quebradiças, semelhantes às lãs de rocha convencionais. As características e propriedades apresentadas pela lã de rocha
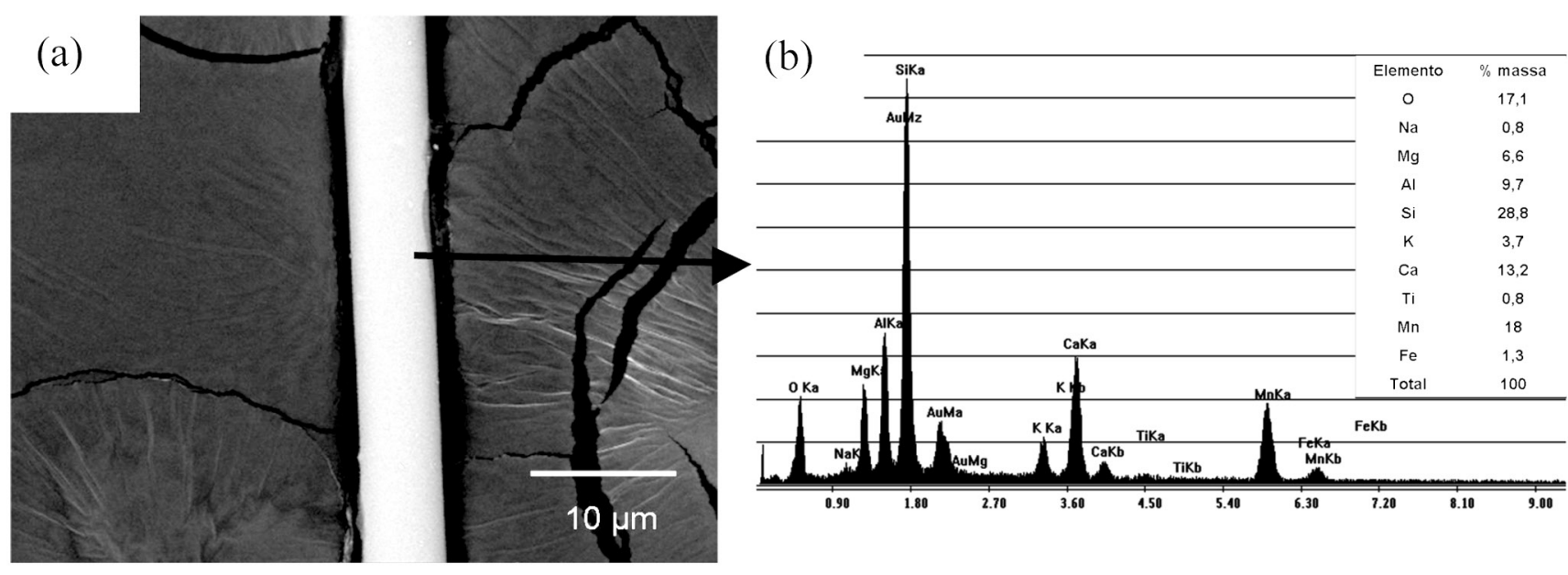

Figura 1: (a) Micrografia de microscopia eletrônica de varredura e (b) espectroscopia de energia dispersiva de raios X (EDS) de uma fibra obtida a partir da escória.

[Figure 1: (a) SEM micrograph and (b) energy dispersive spectroscopy X-ray (EDS) of a fiber obtained from the slag.] 


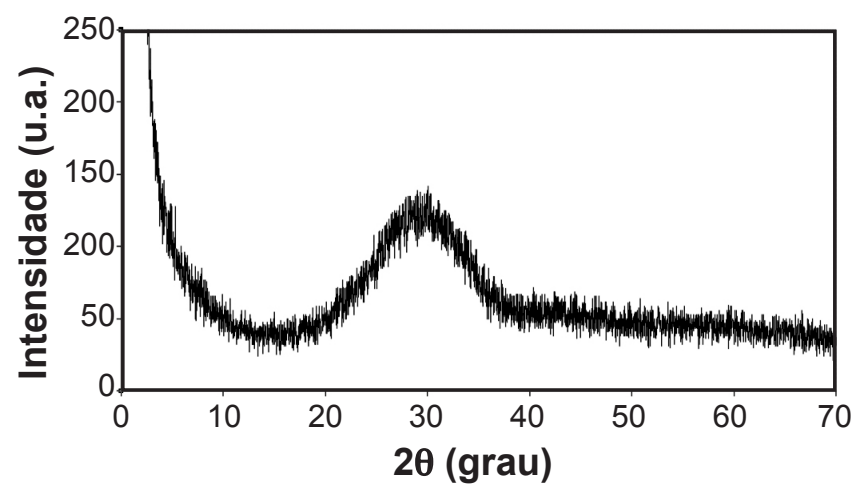

Figura 2: Difratograma de raios $\mathrm{X}$ da fibra obtida com o material que foi vazado em $1450{ }^{\circ} \mathrm{C}$.

[Figure 2: XRD pattern obtained with the fiber material that was leaked in $1450^{\circ} \mathrm{C}$.]

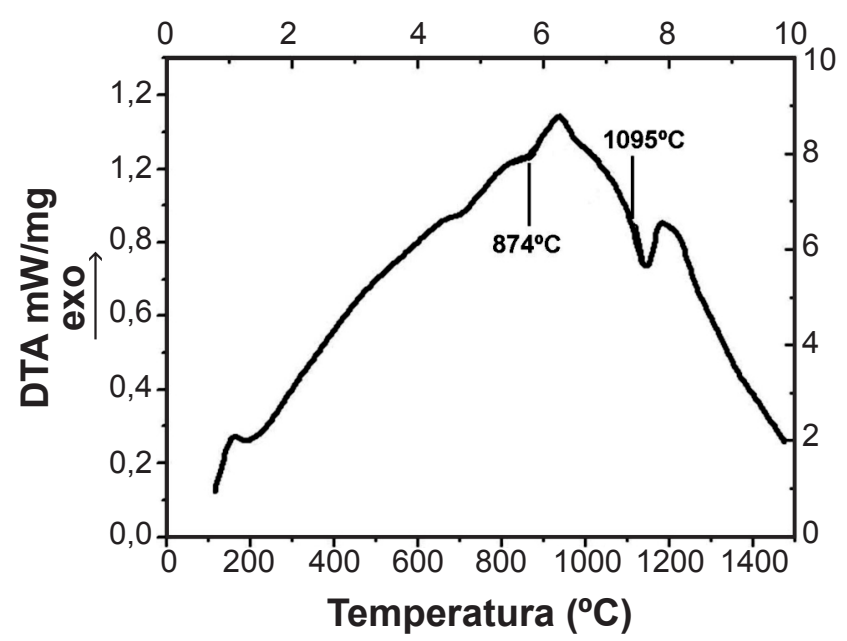

Figura 3: Curva de análise térmica diferencial da fibra obtida através do vazamento em água a temperatura de $1450{ }^{\circ} \mathrm{C}$.

[Figure 3: Curve of differential thermal analysis of the fiber obtained through leaks in water at a temperature of $1450{ }^{\circ} \mathrm{C}$.]

fabricada a partir da escória da produção de FeSiMn são semelhantes às das lãs de rocha convencionais, mostrando que a produção deste tipo de lã mineral utilizando o resíduo é viável, pois além de diminuir a quantidade de matéria prima natural extraída para a produção desta lã mineral, também fornece um destino para a escória.

\section{CONCLUSÕES}

As fibras produzidas são amorfas e quimicamente homogêneas. As temperaturas de fusão e cristalização estão dentro da faixa de temperatura encontrada em normas para fibras de lã de rocha produzidas com matéria prima convencional. $\mathrm{O}$ fato da lã de rocha produzida ter os mesmos constituintes que a lã de rocha convencional reforça a idéia de a escória servir como matéria prima na fabricação de lã de rocha. Como as propriedades das lãs de rocha analisadas neste trabalho são semelhantes às encontradas na literatura, foi mostrado que mesmo com composições químicas um pouco diferentes atinjam-se as mesmas propriedades, justificando o fato de possuir várias formulações deste tipo de lã de rocha. Essas características afirmam que é possível a produção de lã de rocha utilizando como matéria prima a escória de FeSiMn. Com isso diminui-se a extração de matéria prima natural para a fabricação de lã de rocha, prolongando-se a vida útil das jazidas e também diminui a quantidade de escória a ser descartada no meio ambiente, fornecendo um destino para a escória.

\section{REFERÊNCIAS}

[1] K. Luoto, M. Holopainen, J. Kangas, P. Kalliokoski, K. Savolainen, Dissolution of Short and Long Rockwool and Glasswool Fibers by Macrophages in Flowthrough Cell Culture, Environmental Res. Section A 78 (1998) 25.

[2] IARC, International Agency For Research on Cancer, Monographs on The Evaluation of Carcinogenic Risks To Humans Man-made Vitreous Fibres, World Health Organization 81 (2002).

[3] A. L. Santana, Manganês, Sumário Mineral (2008), Disponível em http://www.dnpm.gov.br/assets/ galeriaDocumento/ SumarioMineral2008/manganes.pdf.

[4] L. M. Nóbrega, N. M. G. S. Rosa, L. E. P. de Campos, J. B. Soares, Avaliação Ambiental de Escória de Ferroligas Aplicada em Revestimentos de Pavimentos em Salvador,

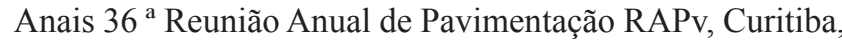
PR, Brasil (2005).

[5] K. N. Demidov, L. A. Smirnov, S. I. Kuznetsov, S. M. Chelpan, A. P. Vozchikov, Use of Slags From the Production of Manganese Alloys in Steelmaking, Metallurgist 44 (2000) 5.

[6] L. Holappa, Y. Xiao, Slags in Ferroalloys ProductionReview of Present Knowledge, VII International Conference on Molten Slags Fluxes and Salts, The South African Institute of Mining and Metallurgy (2004).

[7] M. Pelino, C. Cantalini, F. Veglio, Crystallization of Glasses Obtained by Recycling Goethite Industrial Wastes to Produce Glass-Ceramic Materials, J. Mater. Sci. 29 (1994) 2087.

[8] TIMA, Man-made Vitreous Fibers: Nomenclature, Chemical and Physical Properties, Stamford, CT, OwensCorning Fiberglass, IPCS-WHO 27 (1991).

[9] F. Trdic, B. Sirok, P. R. Bullen, D. R. PHILPOTT, Monitoring Mineral Wool Production Using Real-time Machine Vision. Real-Time Imaging 5, Academic Press, USA (1999) 125.

[10] R. L. Buck, Man-Made Vitreous Fibers, Technical Manual, Navy Environmental Health Center NEHCTM6290.91-1 Rev. A. (1997).

[11] M. A. Schiavon, S. U. A. Redondo, I. V. P. Yoshida, Caracterização térmica e morfológica de fibras contínuas de basalto, Cerâmica 53, 326 (2007) 212.

[12] A. F. Gualtieri, E. Foresti, I. G. Lescib, N. Roveri, L. Dondic, Z. M. Gualtieri, The Thermal Transformation of Man Made Vitreous Fibers (MMVF) and Safe Recycling as Secondary Raw Materials (SRM), J. Hazardous Mater. 162 (2009) 1494. 
[13] L. C. C. Paixão, H. N. Yoshimura, D. C. R. Espinosa, J. A. S. Tenório, Efeito da incorporação de lodo de ETA contendo alto teor de ferro em cerâmica argilosa, Cerâmica 54, 329 (2008) 63.

[14] G. E. Oliveira, J. N. F. de Holanda, Análise do Impacto Ambiental Causado Pela Utilização do Resíduo Sólido do Setor Siderúrgico em Cerâmica Vermelha, Cerâmica 50, 315 (2004) 185.

[15] J. Péra, J. Ambroise, M. Chabannet, Propertie of BlastFurnace Slags Containing High Amounts of Manganese, Cem. Concr. Res. 29 (1999) 171.

[16] J. O. Alves, D. C. R. Espinosa, J. A. S. Tenório,
Recycling of steelmaking slag aiming at the production of thermo-acoustic insulation, Anais TMS 2009, $138^{\text {th }}$ Annual Meeting \& Exhibition, San Francisco, EUA (2009) 921.

[17] R. Klingholz, Technology and Production of Man-Made Mineral Fibres Ann Occup Hyg 20, 2 (1977) 153.

[18] P. De Vuyst, P. Dumortier, G. M. H. Swaen, J. C. Pairon, P. Brochard, Respiratory health effects of man-made vitreous (mineral) fibres, Eur. Respir. J. (1995) 2149.

[19] F. Theakston, Air quality guidelines for Europe, Chapter 8.2: Man-made vitreous fibres, $2^{\text {nd }}$ Ed., WHO Regional Office for Europe, Copenhagen, Dinamarca (2000) 1-18. (Rec. 21/12/2011, Ac. 05/05/2012) 